\title{
A reabilitação da epopéia no século XX: o pan-americanismo épico de Toda a América.
}

\begin{abstract}
Ana Luisa Oliveira*
Resumo: No século XIX, alguns pensadores Abstract: In the $19^{\text {th }}$ century, some thinkers declared declararam o gênero épico incapaz de abarcar as the epic genre unable to encompass the problems of the problemáticas do mundo contemporâneo sendo, contemporary world and therefore impractical in that portanto, impraticável neste contexto. Entretanto, ao context. However, by taking an analytical look at the lançarmos um olhar analítico sobre a Literatura Brazilian Literature of the $20^{\text {th }}$ century, we realize that Brasileira do século XX, percebemos que a epopéia, the epic, a dynamic genre par excellence, in the words um gênero dinâmico por excelência, para utilizarmos of Florence Goyet, was recovered as a way of os termos de Florence Goyet, foi retomada como forma reflecting about the questions in vogue in the period. de refletir acerca de questões em voga no período. A To illustrate the process of rehabilitation of the epic fim de ilustrar como se processou esta reabilitação do genre practiced by the Brazilian Modernist school, we gênero épico praticada pela escola modernista analyzed Ronald de Carvalho's book, Toda a América, brasileira, tomaremos o exemplar Toda a América, de in which we found a fruitful union between the modern Ronald de Carvalho, no qual encontramos uma aesthetic of formal and thematic rupture and the profícua união entre a estética moderna de ruptura grandiloquent tone and elevated subject, characteristic formal e temática e o tom grandiloqüente e a matéria of the epic mode. A composition that resulted, as we elevada atávicos ao modo épico. Uma composição que intend to show, in a new and unique epic panresultou, como procuraremos evidenciar, em um Americanism. inédito e singular pan-americanismo épico.
\end{abstract}

Palavras-chave: epopéia; reabilitação; século XX; Keywords: epic; rehabilitation; $20^{\text {th }}$ century; Brazilian Modernismo brasileiro; pan-americanismo épico. Modernism; epic pan-Americanism.

"Nuestra cultura ha visto el auge y decadencia de la épica" (STEINER, 2000, p. 115)

\section{Primeira Parte}

Como sabemos, alguns pensadores do século XIX criam ser a epopéia incompatível ao mundo moderno, visto que o prosaísmo preponderante nos tempos atuais não preenchia os requisitos de uma verdadeira poesia épica, gênero grandioso por excelência. A atribuição de um caráter obsoleto à epopéia muito se deve ao fato de a épica, em sua origem, versar sobre

\footnotetext{
* Mestranda do Programa de Pós-graduação em Literatura Portuguesa da Universidade de São Paulo e bolsista da FAPESP. E-mail: isaludovica@gmail.com
} 
episódios monumentais e heróicos, próprios aos momentos inaugurais de uma valorosa nação. Nesse sentido, uma vez que, na modernidade, nada de tão elevado e de tão grandioso encontrava-se em curso, foi declarada a aversão desse gênero à modernidade. Seguindo esse raciocínio, afirma Daniel Madelénat. "O campo literário não é mais acolhedor à épica: nele, a poesia somente sobrevive curta e estrófica (...); A estética moderna do fragmento, do inacabado, do amorfo e do caótico menospreza a unidade do universo heróico e a coerência da obra épica." (MADELÉNAT, 1986, p. 248) ${ }^{1}$

Contudo, contrariando este processo de marginalização da epopéia e desmentindo o pensamento geral formulado por Georges Steiner (2000), recentes estudos apontam que, em verdade, o gênero épico nunca encontrou um fim. Para Florence Goyet, "afirmação corrente vislumbra a epopéia enquanto um gênero estático, da celebração e da transparência de valores. (...) existe uma outra maneira de entrever a epopéia; como o gênero dinâmico por excelência, aquele que problematiza as situações e os valores políticos.” (GOYET, sous presse, p. 1.) ${ }^{2}$

Em seu artigo, GOYET (sous presse) analisa obras ocidentais e orientais que, segundo seu ponto de vista, constituem-se enquanto epopéias de nossa época. Com efeito, ao lançarmos um olhar retrospectivo ao cânone literário brasileiro, constatamos que alguns de nossos poetas do século XX retomaram este gênero com o intuito de refletir acerca de questões em voga no período. Dessa forma, encontramos escritores imbuídos da tentativa de desafiar a aparente incompatibilidade entre a modernidade - o Modernismo brasileiro - e a poesia épica, em consonância ao pensamento expresso por Florence Goyet (sous presse): a intenção de unir os elementos modernos, a estética de ruptura formal e temática, aos épicos, como o tom grandiloquiente e a matéria elevada, em um todo coeso.

Sob este prisma, em conseqüência imediata do dinamismo épico, a reabilitação da epopéia no século XX pressupõe uma adequação aos novos conceitos intrínsecos à realidade moderna. Uma revitalização fez-se necessária e incontornável, o que produziu importantes contribuições para a Literatura Brasileira.

Como forma de vislumbrarmos o modo pelo qual tal reabilitação se operou, tomaremos como corpus deste estudo a obra Toda a América (1926), de Ronald de Carvalho,

\footnotetext{
${ }^{1}$ Tradução de própria lavra. Segue o excerto original: "Le champ littéraire n’est pas plus accueillant à l'épique: la poésie n'y subsiste que courte et strophique (...); L'esthétique moderne du fragment, de l'inachevé, de l'amorphe et du chaotique déprécie l'unité de l'univers héroïque et la cohérence de l'oeuvre épique." (MADELÉNAT, 1986, p. 248)

${ }^{2}$ Tradução de própria lavra. Segue o excerto original: “L'affirmation courante voit dans l'épopée le genre statique, de la célébration et de la transparence des valeurs. (...) il y a une autre façon d'envisager l'épopée; comme le genre dynamique par excellence, celui qui problématise les situations et les valeurs politiques."(GOYET, sous presse, p. 1).
} 
texto que se filia, concomitantemente, à fase inicial do movimento Modernista brasileiro e ao gênero épico. Entretanto, antes de adentrarmos propriamente nos meandros deste longo poema, faz-se imprescindível atentarmos a algumas questões relevantes concernentes a trajetória literária de seu autor.

Ronald de Carvalho (1893-1935) elabora seus escritos no começo do século passado, período no qual novas temáticas, impensáveis até então, passam a ser mote literário, como o prosaísmo cotidiano versificado liricamente por Manuel Bandeira. Trata-se também de um momento em que muito se reflete acerca do Brasil, da identidade brasileira e do papel submisso que todo o continente americano exerce no concerto das nações, o "panamericanismo". Em resumo, este tema versa acerca da valorização da terra americana, do homem americano face à cultura européia, tida como imperialista, intrusa e estranha, abordagem que visava, de certa forma, pôr fim à sujeição americana.

Esta temática torna-se uma das principais preocupações do jovem Ronald de Carvalho. Em sua Pequena História da Literatura Brasileira (1919), no capítulo conclusivo, temos a seguinte afirmação:

O homem moderno do Brasil deve, para criar uma literatura própria, evitar toda espécie de preconceitos. Ele tem diante dos olhos um grande mundo virgem, cheio de promessas excitantes. Organizar esse material, dar-lhe estabilidade, reduzi-lo à sua verdadeira expressão humana, deve ser a sua preocupação fundamental. Uma arte direta, pura, enraizada profundamente na estrutura nacional, uma arte que fixe todo o nosso tumulto de povo em gestação, eis o que deve procurar o homem moderno do Brasil. Para isso, é mister que ele estude não só os problemas brasileiros, mas o grande problema americano. $\mathrm{O}$ erro primordial das nossas elites, até agora, foi aplicar ao Brasil, artificialmente, a lição européia. Estamos no momento da lição americana. Chegamos, afinal, ao nosso momento" (CARVALHO, 1949, p. 370).

A partir desse excerto, podemos presumir qual é o projeto estético modernista do poeta: falar de sua terra, do Brasil e da América, cantá-la de forma autêntica, a fim de evidenciar a igual originalidade da matéria abordada - celebrar com força telúrica o novo e promissor continente, objetivando contrapô-lo ao continente europeu, a velha Europa, arcaico e arcaizante. Esse propósito modernista parece ter encontrado seu justo desenvolvimento literário na obra Toda a América, na qual o autor elaborou um trabalho de constituição da identidade americana em oposição à alteridade européia. Neste tocante, afirma o crítico José Aderaldo Castello:

O livro constitui verdadeiro poema de reconhecimento de uma identidade americana (...) posta em confronto com a matriz européia, invocada com este objetivo, conforme a composição que abre o poema. (...) Sem dúvida, Ronald de Carvalho integra-se no pan-americanismo em voga no primeiro quartel do século atual (...). (CASTELLO, 1999, p. 163-164) 
Para tanto, em uma clara adequação entre forma e conteúdo, o poeta busca na forma épica a estrutura necessária a seu projeto: à celebração da América faz-se necessário o tom grandiloqüente da epopéia. Entretanto, como já dito, toda revitalização de um gênero pressupõe transformações e, para melhor percebemos como se processa esta reabilitação da voz épica no Modernismo brasileiro, passemos a uma breve leitura do poema.

\section{Segunda Parte}

Do ponto de vista formal, em Toda a América, notamos uma escrita revolucionária em conformidade com a estética de ruptura proposta pelo Modernismo. Trata-se de um poema longo de caráter narrativo, com versos brancos e livres e com estrofes irregulares, nas quais o ritmo desenvolve-se a passos largos, à moda de Walt Whitman, poeta norte-americano de grande ascendência. Com efeito, o ritmo dos versos constitui uma preocupação de Ronald de Carvalho, que chega a proclamar: "Cria teu ritmo livremente!” (GÓES, 1935, p. 07), máxima que leva a cabo em sua obra, como podemos constatar pelo seguinte verso acerca da América, "Ah! Os tumultos do nosso sangue temperado em saltos e disparadas sobre pampas, savanas, planaltos, caatingas onde estouram biadas tontas, onde estouram batuques de cascos, tropel de patas, torvelinho de chifres!" (CARVALHO, 1935, p. 10)

No que concerne à estrutura, esse poema é dividido em algumas partes: "Advertência", "Brasil”, "Cartas" e "Jornal dos Planaltos", sendo as duas inaugurais mais breves e as duas últimas mais longas. Na primeira delas, seguindo o projeto literário pautado pelo "pan-americanismo", , temos a construção do caráter e da cultura européia, como meio de, nos seguintes momentos do texto, edificar a identidade americana. Nesse sentido, valendose de um tom acentuadamente disfórico, o eu-poético começa a adjetivar o espaço e os costumes europeus enquanto elementos limitados e mesquinhos: “(...) na tua casa de madeira, pequenina, coberta de hera / (...) na tua sala de jantar, em que os teus avós leram a Bíblia e discutiram casamentos, colheitas e enterros,"(idem, 1935, p. 09).

O caráter do povo europeu é tratado de igual maneira pejorativa, com alusões a uma excessiva disciplina e a uma certa falta de desenvoltura, "Europeu! Filho da obediência, da economia e do bom-senso, / tu não sabes o que é ser americano", em clara contraposição ao

\footnotetext{
3 Dada a brevidade deste estudo, não será possível estabelecer um diálogo com outras literaturas latinoamericanas, como a argentina, para as quais o tema pan-americano foi, e ainda é, tão caro. Contudo, este paralelo se faz necessário para que haja uma visão mais aprofundada e ampla acerca desta temática, um estudo que pretende ser matéria de novas considerações em momento oportuno.
} 
modo americano de ser, alegre, genuíno e inventivo, como no trecho: "Alegria de inventar, de descobrir, de correr! / Alegria de criar o caminho com a planta do pé!” (idem, 1935, p. 11).

Já na segunda parte do poema, intitulada "Brasil", encontramos a comunhão entre o conteúdo modernista, o tema da afirmação da identidade americana, que começa a ser feita a partir do Brasil, com um aspecto formal da épica: o tom grandiloqüente celebra a América “Eu ouço o canto enorme do Brasil!" (idem, 1935, p. 12). Como forma de principiar a definição da identidade americana, "heterogênea" (CASTELLO, 1999, p. 163) e diversificada por natureza, dada a vastidão territorial do continente americano, o eu-poético passa a enumerar tudo aquilo que ele denomina como o "canto" do Brasil, ou seja, as particularidades brasileiras:

Eu ouço o tropel dos cavalos de Iguaçu correndo na ponta das rochas nuas, empinando-se no ar molhado, batendo com as patas de água na manhã de bolhas e pingos verdes;

Eu ouço a tua grave melodia, a tua bárbara e grave melodia, Amazonas, a melodia da tua onda lenta de óleo espesso, que se avoluma, lambe o barro das barrancas, morde raízes, puxa ilhas e empurra o oceano mole como um touro picado de farpas, varas, galhos e folhagens;

Eu ouço a terra que estala no ventre quente do nordeste, a terra que ferve na planta do pé de bronze do cangaceiro, a terra que se esboroa e rola em surdas bolas pelas estradas de Juazeiro, e quebra-se em crostas secas, esturricadas no Crato chato;

Eu ouço o chiar das caatingas - trilos, pios, pipios, trinos, assobios zumbidos, bicos que picam, bordões que ressoam retesos, tímpanos que vibram límpidos, papos que estufam, asas que zinem, zinem, zinem, rezinem, cris-cris, cicios, scimas, scimas longas, langues - caatingas debaixo do céu!. (...)" (CARVALHO, 1935, p. 13)

Ao observarmos o trecho acima, mais especificamente o modo que o poeta utiliza para mostrar ao seu leitor a multiplicidade brasileira de sons, de cores, de climas, de vegetações e de recantos, percebemos o emprego do recurso épico ao catálogo, técnica descritiva da enumeração acumulativa, expediente amplamente explorado durante todo o livro.

Segundo Pierre Brunel, importante estudioso dos gêneros literários, o catálogo "está, talvez, na origem mesmo da epopéia" (BRUNEL, 2003, p. 203) ${ }^{4}$ e sempre figura em momentos nos quais se busca dizer a totalidade de algo. Nas epopéias de Homero, encontramos célebres exemplares: na Ilíada temos o catálogo das naus e o catálogo troiano (cf. AUBRETON, 1956, p. 35), este último sendo a relação dos guerreiros mortos antes dos acontecimentos narrados, e na Odisséia encontramos o catálogo dos pretendentes, dos aspirantes a Rei de Ítaca mortos por Odisseu (cf, AUBRETON, 1956, p. 45). Nesse sentido, vemos que a acumulação grandiosa é central em uma obra de estilística épica, não importando o momento histórico no qual ela se situe.

\footnotetext{
${ }^{4}$ Tradução de própria lavra. Segue o excerto original: “est peut-être même à l'origine de l'épopée" (BRUNEL, 2003, p. 203).
} 
Contudo, ainda de acordo com Brunel, quando se busca dizer a totalidade de algo sem nunca chegar a um fim, por meio de uma vasta listagem, o efeito de sentido que se obtém é o

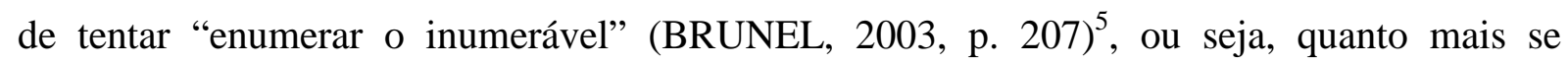
enumera, mais se transmite ao leitor "a impossibilidade de dizer tudo" (idem, 2003, p. 207) ${ }^{6}$, como se o discurso não fosse capaz de dar conta da imensidão do que é narrado, acarretando uma inevitável sensação de magnitude e de grandiosidade acerca da matéria abordada. Em Toda a América, encontramos a precisa aplicação deste efeito grandiloqüente do catálogo. Na medida em que avançamos a leitura da composição "Brasil", cujo excerto encontra-se acima citado, tem-se, de mais a mais, a nítida noção da amplitude do território brasileiro e da infinita diversidade própria a esta terra.

Vale ressaltar que a insistente afirmação do sujeito poético - "Eu (...)/ Eu (...)/ Eu (...)" (CARVALHO, 1935, p. 12) - finda por intensificar o sentido de magnitude impresso ao poema. Visto que, temos a impressão de que o eu-poético também se engrandece na medida em que descreve a opulência da matéria narrada, como se o "eu" abandonasse paulatinamente sua individualidade e assumisse a voz de todos os brasileiros, uma voz coletiva, épica por natureza, que tudo conhece de sua terra.

Ainda no que tange ao catálogo, este recurso reincide enfaticamente na terceira parte da obra, "Cartas", momento no qual o eu-poético começa a descrever os espaços americanos, em uma viagem deslumbrada, indubitavelmente épica, por todo continente, América do Sul, América Central e América do Norte. Os recantos catalogados são correspondentes aos nomes dados aos pequenos poemas que constituem esta composição: "Mercado de Trinidad", referente à ilha caribenha de Trinidad e Tobago; "Noturno das Antilhas", uma passagem noturna pelo mar caribenho; "Barbado", visita ao mais oriental dos países do Caribe; "Brodway", menção à América do Norte; "Tonalá", município mexicano; "Puente Del Inca", alusão ao povoado que fica próximo ao pico do Aconcágua; "Uma noite em Los Andes", visita ao Chile; "Cristal Marinho", relato das semelhanças entre Costa e Continente e "Entre Buenos Aires e Mendoza”, acerca dos pampas.

Dessa forma, a preocupação de tentar dizer a totalidade do continente americano torna-se evidente, principalmente porque, a cada poema, mais características da diversidade americana são elencadas, em lugares com especificidades marcantes, que, juntas, compõem, como dissemos, uma identidade americana heterogênea, naturalmente bela e abundante,

\footnotetext{
${ }^{5}$ Tradução de própria lavra. Segue o excerto original: “dénombrer l'innombrable” (2003, p. 207).

${ }^{6}$ Tradução de própria lavra. Segue o excerto original: "l’impossibilité de tout dire” (2003, p. 207).
} 
Mercado de Trinidad

na tepidez molhada da manhã!

Doirados tropicais de asas e frutas,

Verdes marítimos franjados de Alcatrazes,

Mar de corais, fogos de madrepérolas ao sol. (CARVALHO, 1935, p. 17)

Genuinamente selvagem e rústica,

E esse vento silvestre que passa pelos meus cabelos,

e esse gorgolejo de onda que se parte nos meus ouvido,

e essa umidade salina do deck vazio,

tudo isso é primitivo como um descobrimento (CARVALHO, 1935, p. 19)

Progressista e dinâmica nos grandes centros,

Aquele chão [da Brodway] carrega todas as imaginações do mundo! (...)

Aquele chão é a paisagem em marcha!

Chão que mistura as poeiras do Universo e onde se confundem todos os ritmos do passo humano. (CARVALHO, 1935, p. 22-23)

Industrial nos pólos urbanos e "Eu vi o pampa! (...) Eu vi a luz da aurora, pulando ágil na cobertura de zinco dos longos frigoríficos retangulares" (CARVALHO,1935, p. 34)formada por um povo mestiço, "moreno" (idem, 1935, p. 15) cuja miscigenação é o fator que permite o reconhecimento identitário marcado pela diversidade.

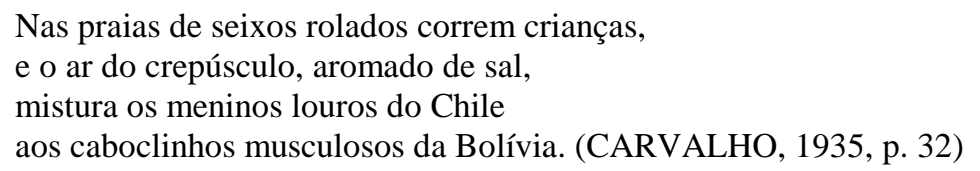

Como podemos constatar, neste longo poema de forma moderna, a terra americana é engrandecida por meio do tom épico grandiloqüente, que celebra e cataloga incansavelmente suas enaltecidas belezas, não cabendo aqui a menção a aspectos de cunho negativo. Com efeito, Ronald de Carvalho revitaliza, com vago espírito romântico, um "sentimento nativista", ao abordar com força telúrica a América, um espaço largamente observado pelo eupoético e descrito de forma id́lica. Neste tocante, parece-nos que o poeta modernista revisita um topus literário de matriz clássica, o locus amoenus, que, segundo Ernst Curtis, encontra sua vigência desde a Antiguidade, nos poemas pastoris de Teócrito e de Virgílio, até a Europa Moderna (1996, p. 254).

De acordo com Demétrio Calderón, o locus amoenus concretiza-se na descrição de paisagens idealizadas, "onde a beleza e a harmonia são pintados com os elementos recorrentes dos prados verdes, frescos cheios de flores (...).”(1996, p. 638). Dessa forma, em Toda a América, constrói-se uma paisagem permeada da "tranqüilidade de todas as ervas atlânticas" (1935, p. 19), de "livres solidões selvagens" (CARVALHO, 1935, p. 18), de "alegria virgem 
de rios-mares, enxurradas, planícies cósmicas picos e grimpas, terras livres, ares livres, florestas sem lei” (CARVALHO, 1935, p. 10).

Ainda consoante Calderón, "estas paisagens idealizadas são habitualmente descritas de forma a desencadear a calma e o bem-estar; ou mesmo a proporcionar determinadas reflexões ou estados de espírito como o amor" (1996, p. 638). Como vimos, o eu-poético assume uma postura contemplativa diante da magnitude de sua terra, em observações que culminam na vasta enumeração da diversidade americana. Em conseqüência a esta atitude de observação, surge, na quarta e última parte de Toda a América, uma importante reflexão que nos remete, inevitavelmente, ao projeto estético de Ronald de Carvalho expresso em sua Pequena História da Literatura Brasileira.

Em “Jornal dos Planaltos", em um primeiro momento, encontramos algumas breves crônicas acerca de episódios presenciados pelo sujeito poético durante sua viagem pela América, em uma clara incorporação da preocupação modernista de versificar o prosaísmo cotidiano:

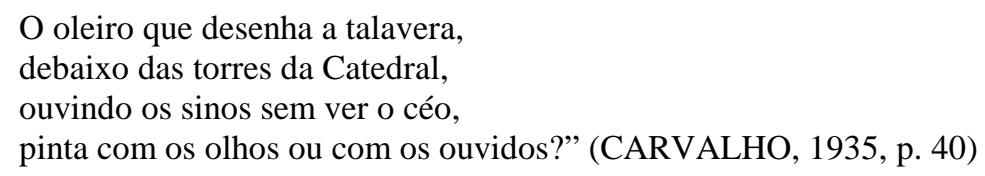

Posteriormente, surge uma derradeira composição intitulada de forma homônima ao livro, “Toda a América”, que é uma espécie de conclusão meta-poética. Em resumo, o sujeito poético assegura ter a América uma força vital milagrosa, fruto de seu caráter multifacetado e de sua mistura de raças, idéia dispersa por toda a obra e aqui sintetizada.

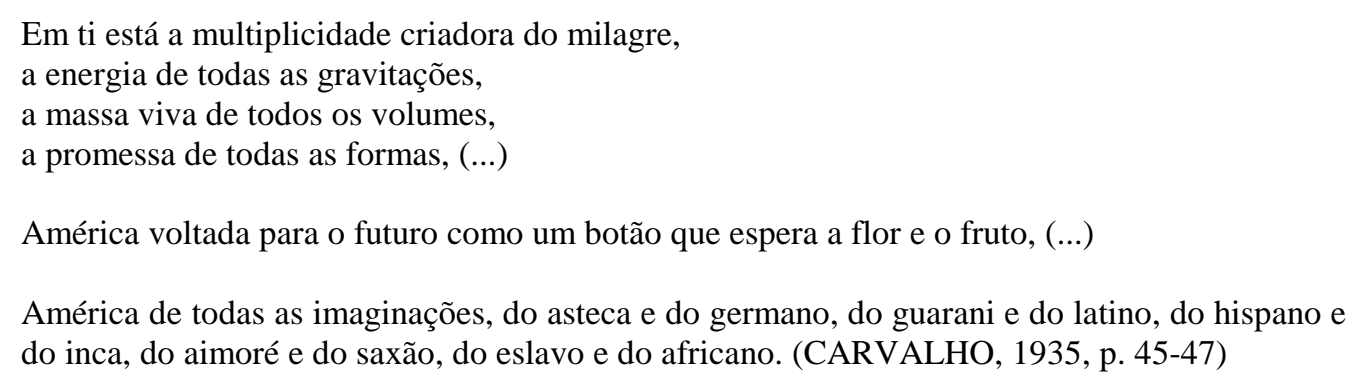

Desse modo, temos uma voz que clama pelo futuro e crê na plena capacidade americana de engendrar melhores dias, momentos inauditos de prosperidade, "O mundo nasce outra vez em ti, e o homem diante de ti sorri ingenuamente como um deus." (CARVALHO, 1935, p. 48) Neste instante, Ronald de Carvalho começa a dar forma a seu programa literário: a voz poética chama pelos poetas americanos que parecem não vislumbrar o potencial 
americano de renovação, que não se debruçam sobre a vasta matéria telúrica que necessita ser cantada e descoberta por seu povo.

Onde estão teus poetas, América?

Onde estão eles que não se debruçam sobre os trágicos suores das tuas sestas bárbaras? (...)

Onde estão eles que não vêem o alarido construtor dos teus portos (CARVALHO, 1935, p. 53).

Em seguida, notamos que o sujeito poético possui uma visão positiva acerca dos poetas americanos, visto que demonstra confiar no potencial latente destes futuros proclamadores de sua terra:

\footnotetext{
Teus poetas não são dessa raça de servos que dançam no compasso de gregos e latino, teus poetas devem ter as mãos sujas de terra, de seiva e limo, as mãos da criação!(...)

Teu poeta será ágil e inocente, América!” (CARVALHO, 1935, p. 55)
}

Precisamente desta forma evocativa o poema se finda, com um sujeito poético que parece vociferar ao poeta americano que é chegada a hora de sentir-se enraizado a sua terra e de crer e exaltar o imenso potencial americano, em plena comunhão com os anseios estéticos pan-americanistas afirmados por Ronald de Carvalho.

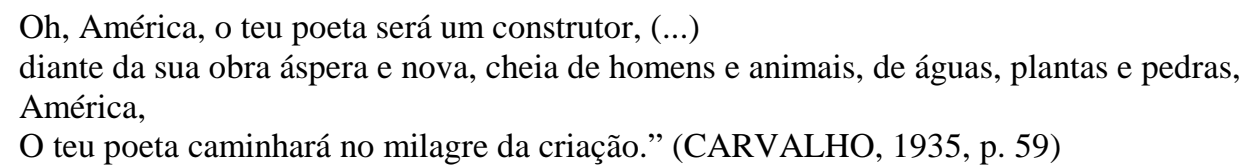

Nesse sentido, podemos constatar que o poema em tela insere-se no projeto literário modernista de Ronald de Carvalho, um programa que foi buscar na forma épica, "o gênero dinâmico por excelência" (GOYET, sous presse, p. 1.), o modo necessário para dar vazão à eufórica celebração da América. Uma reabilitação do gênero épico, marcadamente moderna e pan-americana: uma epopéia com estrutura formal flexível, com versos e estrofes livres, e a abordagem de certos conteúdos à moda modernista, como as pequenas crônicas de "Jornal dos Planaltos", que, entretanto, teve elementos preservados e muito bem explorados, como o marcante tom grandiloquiente, imprescindível à grandiosa exaltação da América, e o emprego do recurso do catálogo, fundamental à enumeração e ao registro da diversidade americana e da composição da identidade americana heterogênea. Assim sendo, não podemos deixar de ressaltar, trata-se aqui de uma retomada que muito antes de poder ser considerada, simplesmente, uma revisitação formal, denota o quão enriquecido e transformado um gênero pode ser a partir do confronto altamente fecundo entre tradição e modernidade.

Em síntese, podemos inferir que o aparente desaparecimento da epopéia proclamado no século XIX, dada a sua incompatibilidade junto ao prosaísmo do mundo moderno, não 
encontra aplicabilidade, uma vez que o gênero épico não desapareceu, mas sim passou por um processo de adequação à nova conjuntura literária e histórica. Uma transformação sempre possível, segundo o critério estético de cada autor. No presente caso, uma revitalização do mais antigo dos gêneros que tornou viável a celebração do novo continente, em uma fusão fecunda e surpreendente que trouxe para o cânone literário brasileiro um exemplar inaudito de “epopéia pan-americana”. Por fim, faz-se imprescindível notar que o legado de Ronald de Carvalho não se restringe a esse longo poema de inspiração épica: trata-se de uma obra ainda não detidamente analisada em toda sua originalidade e em sua complexidade pela crítica literária, que, como procuramos mostrar, é merecedora de apreciações mais aprofundadas, estudos que, em muito podem contribuir para um conhecimento mais efetivo, não só da abordagem do tema pan-americano por escritores brasileiros, mas também da Literatura Brasileira do período modernista.

\section{Referências}

AUBRETON, Robert. Introdução a Homero. São Paulo:Universidade de São Paulo,1956.

BRUNEL, Pierre. Mythopoétique des genres. Paris: Presses Universitaire de France, 2003.

CALDERÓN, Demetrio E. Diccionario de Términos Literarios. Madrid: Alianza Editorial, 1996.

CARVALHO, Ronald. Pequena História da Literatura Brasileira. Rio de Janeiro: Briguet, 1949.

Toda a América. Rio de Janeiro: Hispano-Brasilena ,1935.

CASTELLO, José Aderaldo. A Literatura Brasileira, Origens e Unidade. vol. II. São Paulo: Edusp, 1999.

CURTIUS, Ernst R. Literatura Europeia e Idade Média Latina. São Paulo: Edusp/Hucitec, 1996.

GÓES, Eurico. Prólogo - Ronald de Carvalho. In: CARVALHO, Ronald. Toda a América. Rio de Janeiro: 1935. p. 5-7.

GOYET, Florence. L'epopée comme outil intellectuel. In NEIVA, Saulo (org.). Déclin et confins de l'épopée au XIXe siècle Paris: Clermont-Ferrand, PUBP, no prelo.

MADELENAT, Daniel. L'epopée. Paris: Presses Universitaires de France, 1986.

STEINER, Georges. Lenguaje y Silencio. $2^{\mathrm{a}}$ ed. Barcelona: Gedisa, 2000. 